\title{
EFFECT OF ACETYL-L-CARNITINE ON VIP-ERGIC NEURONS IN THE JEJUNUM SUBM UCOUS PLEXUS OF DIABETIC RATS
}

\author{
Marli Aparecida Defani ${ }^{1}$, Jacqueline Nelisis Zanoni², Maria Raquel Marçal Natali², \\ Roberto Barbosa Bazotte ${ }^{3}$, Marcílio Hubner de Miranda-Neto²
}

\begin{abstract}
The effect of the treatment with acetyl-L-carnitine (ALC) on neurons releasing the vasoactive intestinal polypeptide (VIP) of the submucous plexus in the jejunum of diabetic rats was the purpose of our investigation. Diabetes (DM) was induced by injecting streptozotocin endovenously (35mg/kg). After sacrificing the animals, the jejunum was collected and processed for VIP detection. Four groups were used: C (nondiabetic), CC (non-diabetic treated with ALC), D (diabetic), DC (diabetes treated with ALC). We analyzed the immunoreactivity and the cellular profile of 126 cell bodies. The treatment with ALC improved some aspects of DM. However, it promoted a small increase in the area of neurons from group CC, suggesting a possible neurotrophic effect. Neurons from groups D and DC showed a large increase in their cellular profile and immunoreactivity when compared to $\mathrm{C}$ and CC, suggesting a larger concentration of this neurotransmitter within the neurons that produce it. This observation constitutes a recurrent finding in diabetic animals, suggesting that ALC doesnot interfere in the pathophysiological mechanisms that unchain a higher production and/or neurotransmitter accumulation and increase the profile of the VIP-ergic neurons.
\end{abstract}

KEY WORDS: acetyl-L-carnitine, submucous plexus, VIP, diabetes, jejunum, rat.

\section{Efeito da acetil-L-carnitina sobre neurônios Vip-érgicos do plexo submucoso do jejuno de ratos diabéticos}

RESUMO - Investigamos o efeito da acetil-L-carnitina (ALC) sobre os neurônios que expressam o peptídeo intestinal vasoativo (VIP) do plexo submucoso no jejuno de ratos diabéticos. O diabetes (DM) foi induzido pela administração endovenosa de estreptozootocina (35mg/ $/ \mathrm{kg}$ ). Após o sacrifício dos animais, o jejuno foi coletado e processado para a detecção de VIP. Utilizou-se quatro grupos: C (não diabéticos), CC (não diabéticos suplementados com ALC), D (diabéticos) e DC (diabéticos suplementados com ALC). Analisou-se a imunoreatividade e o perfil celular de 126 corpos celulares. O tratamento com ALC melhorou alguns aspectos do DM. Porém, promoveu pequeno aumento na área dos neurônios do grupo CC, indicando possível efeito neurotrófico. Neurônios dos grupos D e DC apresentaram grande aumento do perfil celular e na imunoreatividade em relação a C eCC, sugerindo maior concentração deste neurotransmissor nestes neurônios. Esta observação é constante em animais diabéticos, sugerindo que a ALC não interfere nos mecanismos fisiopatológicos que desencadeiam a maior produção e/ou acúmulo de neurotransmissor e aumento do perfil dos neurônios VIP-érgicos.

PALAVRAS-CHAVE: acetil-L-carnitina, plexo submucoso, VIP, diabetes, jejuno, rato.

Diabetes mellitus (DM) main chronic complications are, among others, vascular changes and peripheral neuropathies, which lead to gastrointestinal dysfunctions. Several hypotheses have been reported concerning the main causes for the origin of the diabetic neuropathy. Recent reports have described that the carnitine abnormal metabolism may be one of the reasons that triggers neural damage, associated to sorbitol accumulation, fructose and mioinositol depletion in the nervous cells $\mathbf{s}^{1,2}$. DM may have a differentiated effect under the different enteric neuroactive substances. Studies have shown different responses of the adrenergic, serotonergic and peptidergic nerves and of the enteric plexus in streptozotocin-diabetic rats r,4. $^{3,}$.

The vasoactive intestinal polypeptide (VIP) is a neurotransmitter located in neurons of the gastrointestinal tract and seems to have a pluripotent role in

\footnotetext{
State University of Maringá (UEM), Maringá PR, Brazil: ${ }^{1}$ Professor at Department of Sciences; ${ }^{2}$ Professor at Department of Morphophysiological Sciences; ${ }^{3}$ Professor at Department of Pharmacy and Pharmacology. This study was supported by funds from CAPES.
}

Received 5 December 2002, received in final form 10 July 2003. Accepted 21 July 2003.

Dra. M. A. Defani - Department of Sciences, (UEM) - Avenida Reitor Zeferino Vaz s/n Jardim Universitário - 87360-000 Goioerê PR - Brasil. E-mail: mad@visaonet.com.br. 
the regulation of the intestinal motility. It is an important nonadrenergic, noncholinergic neurotransmitter (NANC) of the peripheral nerves, provoking the relaxation of many types of vascular and non-vascular smooth muscles in many parts of the gastrointestinal tract. The anal projection of VIP-ergic neurons in the small and large intestine is compatible with the suggestion that it acts under the descending inhibition in the peristaltic reflex. VIP is found in a great number of neurons of the submucous plexus and it rarely occurs in neurons of the myenteric plexus ${ }^{5}$. In the submucous neurons, it acts controlling the secretion of water and electrolytes of the intestinal mucous membrane and such alterations implicate in disorders of the digestive system ${ }^{6}$, such as the syndrome of the diabetic diarrhea ${ }^{7}$. DM affects the level and secretion of the enteric VIP most likely due to abnormalities in the synthesis mechanism, liberation and/or degradation of VIP ${ }^{8}$. Another consequence of DM is the reduction of the free plasma carnitine and the increase of the ester carnitine, which can lead to the accumulation of long chain fatty acids, thus disturbing the stability and the function of membranes. Besides the previously mentioned functions, carnitine is also essential for the lipidic oxidation and synthesis, being involved in the liberation and stockpiling of metabolic energy ${ }^{9,10}$.

Rats with diabetes mellitus present a dysfunction of the enteric innervation and a carnitine deficiency. Therefore, we studied the effect of the supplementation with acetyl-L-carnitine (ALC) on the sub-population of VIP-ergic neurons of the submucous plexus of the jejunum of streptozotocin diabetic rats.

\section{METHOD}

Animal procedures - Male Wistar rats (Rattus norvegicus) weighing 300-400 g were employed. In order to induce the diabetes, the rats were kept fasting for 14 hours and then streptozotocin $(35 \mathrm{mg} / \mathrm{Kg} / \mathrm{body}$ weight, Sigma, USA) dissolved in $10 \mathrm{mM}$ buffer citrate, $\mathrm{pH}$ 4.5, was injected i.v. Non-diabetic rats were used as control groups. The streptozotocin injection resulted in a diabetic syndrome with rapid weight loss and polydipsia. The rats were divided into 4 groups: non diabetic (group C), non diabetic treated with ALC (group CC), diabetic (group D), and diabetic treated with ALC (group DC). The initial body weight of groups C, CC, D and DC was $362.0 \pm 17.9 \mathrm{~g}, 328.4$ $\pm 6.3 \mathrm{~g}, 361.6 \pm 2.4$ and $367.0 \pm 8.1 \mathrm{~g}$ respectively. ALC was administered for 15 weeks from the onset of the diabetes by the addition of ALC (SPfarma - SãoPaulo-BR) in water $(200 \mathrm{mg} / \mathrm{kg}$, prepared daily). The animals were kept in individual cages in an environment with photoperiod (6:00 - 18:00/light) and controlled temperature ( $24 \pm 2$ 으). The animals received water and Nuvital ${ }^{\circledR}$ balanced lab chow ad libitum. The water intake was monitored biweekly, during the whole experiment. Fifteen weeks after the onset of $\mathrm{DM}$, the rats were anesthetized intraperitoneally with tiopental (40 mg $/ \mathrm{kg} / \mathrm{body}$ weight). The blood was collected by heart puncture to assess glycemia ${ }^{11}$ and hemoglobin ${ }^{12}$.

Morphometric and immunohistochemical analyses After an abdominal incision, the jejunum segments were collected, washed in a phosphate buffer (PBS 0.01M, pH 7.4), and fixed with Zamboni's liquid for 18 hours at $4^{\circ} \mathrm{C}^{13}$. The segments were processed in accordance with the immunohistochemical technique for whole-mount preparations ${ }^{14}$ aiming at detecting VIPs presence in the submucous plexus. Soon afterwards, the segments were open along the mesenteric border, washed and dehydrated, cleared in xylol, re-hydrated and later on kept in PBS 0.01M, pH 7.4. The samples were then reduced with the help of a circular cutter and the mucosa and muscular layers were dissected under stereomicroscopy. The isolated submucous layer was incubated with anti-VIP polyclonal antibody 1:200 for 16 hours (Penninsula Labs, USA). The samples were washed in PBS and then incubated with secondary antibody conjugated with fluorescein (FITC) (Penninsula Labs, USA) 1:100, for $1 \mathrm{~h}$, at room temperature, under agitation. In the control samples, the primary antibody was substituted by goat serum. The whole-mount preparations were mounted with glycerol. The immunofluorescence was analyzed in trinocular biological optical microscope, $40 \mathrm{X}$ lens, equipped with filters for immunofluorescence (FITC) and an IPPWIN-DCAM image taking kit. The images were taken by a high-resolution camera, transmitted to microcomputer and recorded in compact disc.

Through the Image-Pro-Plus 3.0.1 software of image analysis, we measured the area $\left(\mu \mathrm{m}^{2}\right)$ of 126 cellular bodies of immunoreactive VIP-ergic neurons (VIP-IR) in each studied group. We used the mean value and the standard deviation of the measures of the 126 cell bodies of VIP-IR neurons from the control $(C)$ to classify the neurons in small, medium and large. We considered as small those neurons whose values were similar or inferior to the difference between the mean value and the standard deviation. Large neurons were those whose mean values were similar or higher than the sum between the mean and the standard deviation. We called medium neurons those whose mean values were between these values.

Statistical analysis - The data related to body weight, water intake, glycemia and blood glucose were assessed through variance analysis and Tukey test to compare the mean. As the VIP-IR neurons did not present a normal distribution in their cellular body area, we employed the variance analysis and test " $\mathrm{t}$ " of Student to compare the means. The analyses were performed with the Software Prism 2.01. The chi-square test was applied $\left(\chi^{2}\right)$ to analyze the significance of data regarding the frequency of small, medium and large neurons in the different treatments. The significance level in all the tests was of $5 \%$. 
Table 1. Glycemia (GLI), blood glucose (HbG), water consumption (CDA) of non-diabetic animals (C), non-diabetic animals treated with acetyl-L-carnitine (CC), diabetic animals (D) and diabetic treated with acetyl- $L$ carnitine (DC). The results are expressed as mean \pm standard deviation. $\mathrm{n}=5$ rats per group.

\begin{tabular}{cccc}
\hline Group & GL mg dL & HbG/\% & CDA/mL \\
\hline C & $105.4 \pm 11.2^{\mathrm{a}}$ & $3.9 \pm 0.2^{\mathrm{a}}$ & $62.13 \pm 0.9^{\mathrm{a}}$ \\
CC & $99.8 \pm 5.9^{\mathrm{a}}$ & $3.9 \pm 0.2^{\mathrm{a}}$ & $51.1 \pm 1.1^{\mathrm{a}}$ \\
D & $344.4 \pm 15.2^{\mathrm{b}}$ & $6.6 \pm 0.2^{\mathrm{b}}$ & $173.92 \pm 1.6^{\mathrm{b}}$ \\
DC & $286.0 \pm 21.1^{\mathrm{b}}$ & $6.8 \pm 0.3^{\mathrm{b}}$ & $164.6 \pm 7.6^{\mathrm{b}}$ \\
\hline
\end{tabular}

Means followed by different letters in the same column have different values by Tukey test $(p<0.05)$

\section{RESULTS}

Establishing the diabetes and biochemical parameters - Streptozotocin promoted the DM characterized by polydipsia and hyperglycemia (Table 1) and by the smallest weight gain in relation to the nondiabetic rats. The groups C and CC presented, on average, a final body weight of $472 \pm 23.9 \mathrm{~g}$ and 452.6 $\pm 13.1 \mathrm{~g}$ respectively, while the rats from groups $\mathrm{D}$ and DC presented, on average, a final body weight of $316.6 \pm 3.5 \mathrm{~g}$ and $336.6 \pm 14.1 \mathrm{~g}$ respectively. Therefore, according to these data, the results presented by the groups $\mathrm{D}$ and $\mathrm{DC}$ revealed significant statistical differences when compared to the non-diabetic groups respectively ( $C$ and $C C)(p<0.05)$.

We observed that the ALC-supplementation reduced the glycemia for group DC. However, there was no significant difference $(p>0.05)$ between this group (DC) and group D. The animals from groups D and DC presented high levels of blood glucose in relation to groups C and CC. The ALC-supplementation did not alter the blood glucose levels in the diabetic animals from group $D C$ in relation to group $D(p>0.05)$.

Morphologic analysis - We observed VIP-IR cell bodies in the submucous plexus of the jejunum in the 4 analyzed groups. Group D presented intense immunoreactivity in the nervous fibers and cellular bodies. However, the group CC and group DC presented the highest immunoreactivity (Fig 1).

The VIP-IR cell bodies area averages varied from $306.2 \mu \mathrm{m}^{2}$ (group C) to $535.5 \mu \mathrm{m}^{2}$ (group DC) (Table 2 ). The area of cell bodies from groups $D$ and $D C$ increased significantly in relation to groups $C$ and CC. The ALC-supplementation promoted an increase in the area of the VIP-IR cell bodies from group CC in relation to group $C(p<0.05)$. The area of neurons from group DC was larger than those from group $D$. However, this difference was not significant.
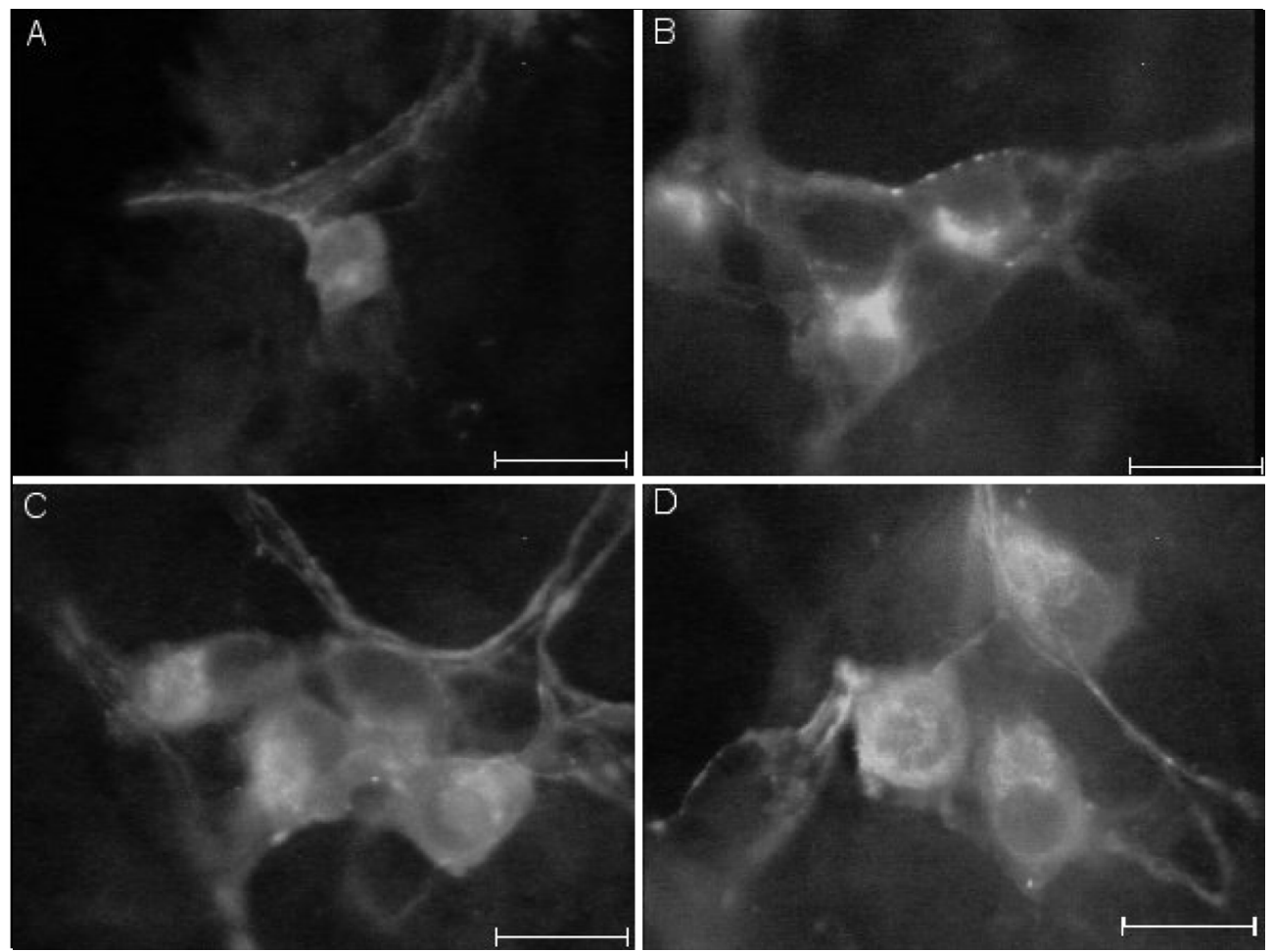

Fig 1. Immunofluorescence micrographs showing imunoreactive VIP-ergic neurons of the jejunum submucous plexus of animals from: A) non-diabetic group, B) non-diabetic group supplemented with acetyl-L-carnitine, C) diabetic group, D) diabetic group treated with acetyl-L-carnitine. Calibration bar: $20 \mu \mathrm{m}$. 


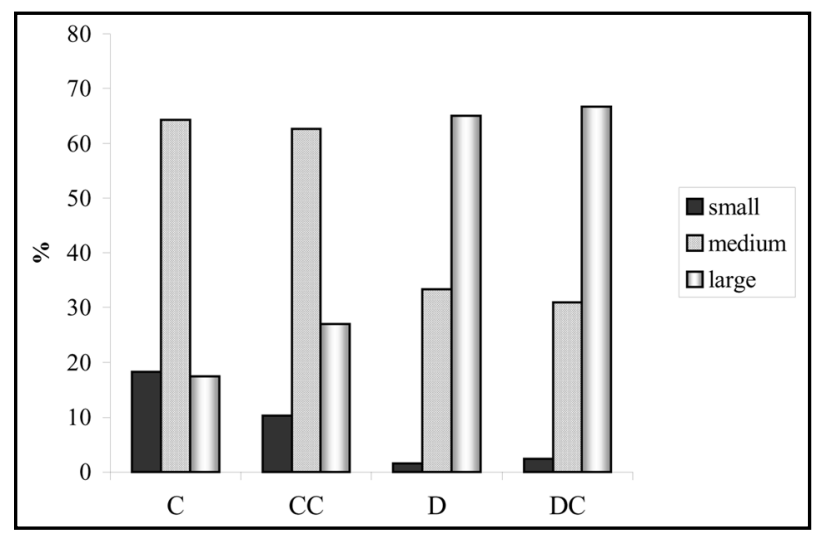

Fig 2. Relative frequence of VIP-ergic neurons, according to their sizes - small, medium and large - of non-diabetic animals (C), non-diabetic animals treated with acetyl-L-carnitine (CC), diabetic animals (D) and diabetic treated with acetyl-L carnitine (DC). $n=$ 5 rats per group.

Table 2. Mean and standard deviation of VIP-IR cell body areas in animals from non-diabetic (C), non-diabetic treated with acetylL-carnitine (CC), diabetic (D) and diabetic treated with acetyl-L carnitine (DC). $n=5$ rats.

\begin{tabular}{cc}
\hline Group & Mean \pm SD \\
\hline C & $306.2 \pm 17.7^{\mathrm{a}}$ \\
CC & $371.3 \pm 16.4^{\mathrm{b}}$ \\
D & $503.8 \pm 15.8^{\mathrm{c}}$ \\
DC & $535.5 \pm 11.9^{\mathrm{c}}$ \\
\hline
\end{tabular}

Means followed by different letters in the same column have different values by $t$ Student test $(p<0.05)$

The neurons were divided in 3 groups according to their sizes: small neurons (with values below 171.8 $\mu \mathrm{m}^{2}$ ), large (with values above $440.6 \mu \mathrm{m}^{2}$ ), and medium (with intermediate values).

Through the test of the $\chi^{2}$, we found significant differences among the small, medium and large neurons when we compared the 4 investigated groups. The same was observed when we compared the groups two by two (CxCC; CxD; CxDC; CC xD; CC $x D C ; D x D C)$. Figure 2 shows the relative frequency of VIP-ergic neurons, according to the classification into small, medium and large. We observed that in the groups $C$ and CC there is a predominance of medium size neurons while in the groups $D$ and DC, the prevalence is of large neurons.

\section{DISCUSSION}

An increase $(p<0.05)$ of the glycemia and blood glucose was observed in group $D$, confirming that these animals had the diabetic syndrome, similar to what was observed by Zanoni et al. ${ }^{15}$. The ALC supplementation did not act immediately in the metabolic control of DM, as evidenced by the similar levels of blood glucose between groups D and DC. On the other hand, although not statistically significant, the glycemia level after fasting was $20 \%$ lower on average in group DC when compared to group $D$. This fact, plus the observation that rats from group DC had a smaller weight loss, may indicate that the supplementation helped improve the carnitine levels, which are vital for the lipidic oxidation and synthesis ${ }^{9,10}$. These results are consistent to the fact that the diabetes leads to a reduction in the levels of mitocondrial ALC, promoting accumulation of fatty acids hindering, therefore, the function of the cell body membranes and of the neurons nervous fibers ${ }^{10}$. The depletion of ALC, which happens in DM, is one of the factors that contribute to the development of the diabetic neuropathy².

We observed an increase in the immunoreactivity to VIP in the submucous plexus of the jejunum in the rats from group $D$, similar to what was observed by Belai $\&$ Burnstock ${ }^{4}$ who evidenced intensely stained VIP-ergic neurons in the submucous plexus of rats, sixand eight weeks after streptozotocin-diabetes. Fourteen weeks after inducing the diabetes with aloxana, the levels of substance $P$ and metionineencephaline were reduced while the levels of the VIP neurotransmitter increased drastically ${ }^{16}$. We can infer that the increase of the immunoreactivity is directly related to the increase of non-liberated VIP levels in the submucous neurons. Changes in the submucous VIP-ergic neurons result in disgestive tract disorders, such as the diarrheic diabetes, since the increase of VIP release results in an increased water and eletrolites secretion, softening the fecces. Similar results were obtained by Belai et al. ${ }^{17}$, who noticed an increase in the immunoreactivity of VIP-ergic neurons. We do believe that the increase in the synthesis of VIP by the mienteric neuron in diabetic rats may have a triggering factor in diminishing the intestinal tonus. This would contribute to the diarrheic diabetes appearance, since a smaller intestinal traffic would enhance the susceptibility to intestinal infections.

The ALC supplementation did not stop the occurrence of a large increase in the immunoreactivity of VIP-ergic neurons of the submucous plexus of the jejunum of diabetic rats. This shows that this substance is less effective than ponalrestat, which in the studies of Belai et al. ${ }^{17}$ stopped the sorbitol formation by inhibiting the enzyme aldose redutase and also stopped the increase of VIP immunore- 
activity and galanina. However, ALC is beneficial for the integrity of the nerve because it preserves the mioinositol content without interfering in the activity of the polyol pathway, since its sorbitol contents is not altered in hyperglycemic rats after treatment with ALC. Another positive aspect is that the lipidic peroxidation, which is intensified in the diabetes, is prevented with $\mathrm{ALC}^{1,18}$. However, as we have already mentioned, it does not reduce the immunoreacivity to VIP in the submucous plexus neurons.

We observed that the area of the cell bodies of VIP-ergic neurons in group CC showed a small but significant increase when compared to group C, along with an increase in the immunoreacivity, which could be related to a possible neurotrophic effect of the carnitine. The expressive increase of the area verified in groups $D$ and DC could be related not only to the increment of the synthesis machinery but also to its accumulation and expression difficulties. We observed an increase in the immunoreactivity to VIP associated to an increase of the area, thus indicating that the accumulation of this substance within the neurons was similar to what was previously observed in VIP-ergic neurons of the terminal ileum of diabetic rats ${ }^{15}$. See et al. ${ }^{19}$ analyzed the submucous VIP neurons of the jejunum of rats after chemical denervation and verified that the area of these neurons increases once the myenteric and extrinsic pulse is removed from the jejunum. However, there is no change in the percentage of submucous neurons expressing VIP. The increase in the cellular size that follows denervation suggests that the extrinsic neural pulse has an inhibitory influence on the submucous nerves since, although the myenteric and the submucous plexus are spatially apart, they form an integrated unit ${ }^{20}$. Thus, the reduction of the inhibitory pulse by the neurons of the myenteric plexus, which are reduced in the chronic $\mathrm{DM}^{21-25}$ for neurons in the submucous plexus, could result in an increase in the VIP production, increasing the area of the cell bodies of the submucous VIP-ergic neurons.

When analyzing the frequency of neurons according to their size, we verified that the groups ( $C$ and $C C$ ) presented a higher number of medium neurons while the diabetic groups ( $D$ and $D C$ ) showed a higher number of large neurons. That demonstrates that there is a significant increase in the areas of the cell bodies of the VIP-ergic neurons, making many neurons change category, i. e., making small neurons change into medium and medium neurons into large ones. The predominance of large neurons was verified by Zanoni et al. ${ }^{21}$ in the cecum of rats with two and eight months of DM. We also observed that ALC does not have any effect on this category change by the neurons, since the results between groups D and DC were similar.

We conclude that ALC promotes the improvement of some aspects of the diabetes such as a smaller body weight loss and improvement in glycemia levels after fasting; however, regarding the cellular aspects, the ALC-supplementation promoted a small increase in the cellular profile area in the neurons of group CC. This may be an indicative of a possible neurotrophic effect. However, when we compared groups D and DC we verified that the VIP-ergic neurons of the submucous plexus of the jejunum of both groups go through a large increase in their cell profile and immunoreacivity when compared to the controls, suggesting a higher concentration of this neurotransmitter inside the neurons that produce it. As this finding is a constant in diabetic animals, there is a probability that the ALC was not capable to interferewith the pathophysiological mechanisms that trigger the higher production and/or accumulation of this neurotransmitter and increase the profile of VIPergic neurons.

Acknowledgements - We would like to thank Natali Kira Tamura - Pharmaceutical Biochemistry - Regional Academical Hospital of Maringá - State University of Maringá; Cristina Helena Teles Prado Fregonesi - Assistant Professor - UNESP - Presidente Prudente Campus, Physiotherapy Department, Sciences \& Technology College (FCT); Angela Alves Pereira - Assistant Professor - UNIOESTE - Biology Department.

\section{REFERENCES}

1. Lowitt S, Malone JI, Salem AF, Korthals J, Benford DS. A cetyl-Lcarnitine corrects the altered peripheral nerve function of experimental diabetes. Metabolism 1995;5:677-680.

2. NakamuraJ, Koh N, Sakakibara F, et al. Polyol pathway hyperactivity is closely to carnitine deficiency in the pathogenesis of diabetic neuropathy of streptozotocin-diabetic rats. J Pharmacol Exp Therap 1998;287:897-902.

3. Ballmann $\mathrm{M}$, Conlon JM Changes in the somatostatin, substance $P$ and vasoadtiveintestinal polypeptidecontent of thegastrointestinal tractfollowing streptozotocin-induced diabetes in the rat. Diabetologia 1985;28:355-358.

4. Belai $A$, Burnstock $G$. Changes in adrenergic and peptidergic nerves in the submucous plexus of the streptozotocin-diabetic rat ileum. Gastroenterology 1990;98:1427-1436.

5. Dockray GJ. Physiology of enteric neuropeptides In Johnson LR (ed). Physiology of the gastrointestinal tract. N ew York Raven, 1994:169-209.

6. Belai A, Linconl J, Milner P, Crowe A, Loesch A, Burnstock G. Enteric nerves in diabetic rats: increase in vasoative intestinal polypeptide but not substance P. Gastroenterology 1985;89:967-976.

7. Modlin IM, Bloom SR, Mitchell SJ. Experimental evidencefor vasoative intestinal peptide as the cause of the watery-diarrhoea syndrome. Gastroenterology 1978;75:1051-1054.

8. Belai A, Facer P, Bishop A, Polak JM, Burnstock G. Effect of streptozotocin-diabetes on level of VIP mRNA in myenteric neurones. Neuroreport 1993;4:291-294.

9. Ferrannini E, Buzzigli G, Bevilacqua S, et al. Interaction of carnitine with insulin-stimulated glucose metabolism in humans. Am J Physiol 1988;255:946-952. 
10. Stevens MJ, Feldman EL, Greene DA. The aetoliogy of diabetic neuropathy: the combined roles of metabolic and vascular defects. Diabetic Med 1995;12:566-579.

11. Bergmeyer HU, Bernet E. Determination of glucose-oxidase and peroxidase. In Methods of enzymatic analysis. New York Academic Press, 1974.

12. Koenig RJ, Peterson CM, Jones RL, Saudek C, Lehrman M, Cerani A. Correlation of glucose regulation and hemoglobin Alc in diabetes mellitus. N Engl J Med 1976;295:417-420.

13. Stefanini M, Demartino C, Zamboni C. Fixation of ejaculated spermatozoa for electron microscopy. Nature 1967;216:173-174.

14. Costa M, Buffa R, Furness JB, Solcia E. Imunohistochemical localization of polypeptides in pheripheral autonomic nerves using whole mount preparations. Histochemistry 1980;65:157-165.

15. Zanoni JN, Hernandes L, Bazotte RB, Miranda - Neto MH. Terminal ileum submucous plexus: study of the VIP-ergic neurons of diabetic rats treated with ascorbic acid. Arq Neuropsiquiatr 2002;60:32-37.

16. Gorio A, DI Giulio AM, Tenconi B, etal. Peptidealterations in autonomic diabetic neuropathy prevented by acetyl-L-carnitine. Int J Clin Pharm Res 1992;12:225-230.

17. Belai A, Calcutt NA, Carrington AL, Diemel LT, Tomlinson DR, Burnstock G: Enteric neuropeptides in streptozotocin-diabetes rats: effects of insulin and aldose reductase inhibition. J Auton Nerv Syst 1996;58:163-169.
18. Hotta N, Koh N, Sakakibara F, et al. Effects of propionyl-L-carnitine on motor nerve conduction, autonomic cardiac function, and nerve blood flow in rats with streptozotocin-induced diabetes: comparison with an aldose reductase inhibitor. J Pharmacol Exp Ther 1996;276:49-55.

19. See NA, Epstein ML, Dahl JL, Bass $P$. The myenteric plexus regulates cell growth in rat jejunum. J Auton Nervous Syst 1990;31:219-229.

20. FurnessJB, CostaAM. Theenteric nervous system, New York, Churchil Livingstone, 1987.

21. Zanoni JN, Miranda- Neto MH, BazotteRB, Souza RR. Morphological and quantitativeanalysis of theneurons of themyenteric plexus of the cecum of streptozotocin-induced diabetic rats. Arq Neuropsiquiatr 1997;55:696-702.

22. Hernandes L, Bazotte RB, Gama P, Miranda-Neto MH. Streptozotocininduced diabetes duration is important to determinechanges in thenumber and basophily of myentericneurons. Arq Neuropsiquiatr 2000;58:1035-1039.

23. Romano BE, Miranda - N eto MH, Cardoso RCS. Preliminary investigation about the effects of streptozotocin-induced chronic diabetes on the nerve cell number and size of myenteric ganglia in rat colon. Rev Chil A nat 1996;14:139-145.

24. Fregonesi CEPT, Miranda-N eto MH, Molinari SL. Estudo morfológico equantitativo dos neurônios do plexo mientérico do corpo do estômago de Rattus norvegicus. Acta Scientiarum 1998;20:221-24.

25. Fregonesi CEPT, Miranda-N eto $\mathrm{MH}$, Molinari SL, Zanoni JN Quantitative study of the myenteric plexus of the stomach of rats with streptozotocin-induced diabetes. Arq N europsiquiatr 2001;59:50-53. 